\title{
Observing Single, Heterogeneous, One-Electron Transfer Reactions
}

Stephanie Zaleski,,$^{\dagger}$ M. Fernanda Cardinal,,$^{\dagger}$ Jordan M. Klingsporn, ${ }^{\dagger}$ and Richard P. Van

$$
\text { Duyne } e^{\dagger, \#, \xi *}
$$

$\dagger$ Northwestern University, Department of Chemistry, 2145 Sheridan Road, Evanston, IL 60208, United States

\#Northwestern University, Department of Biomedical Engineering, 2145 Sheridan Road, Evanston, IL 60208, United States

$\S$ Northwestern University, Program in Applied Physics, 2145 Sheridan Road, Evanston, IL 60208, United States 


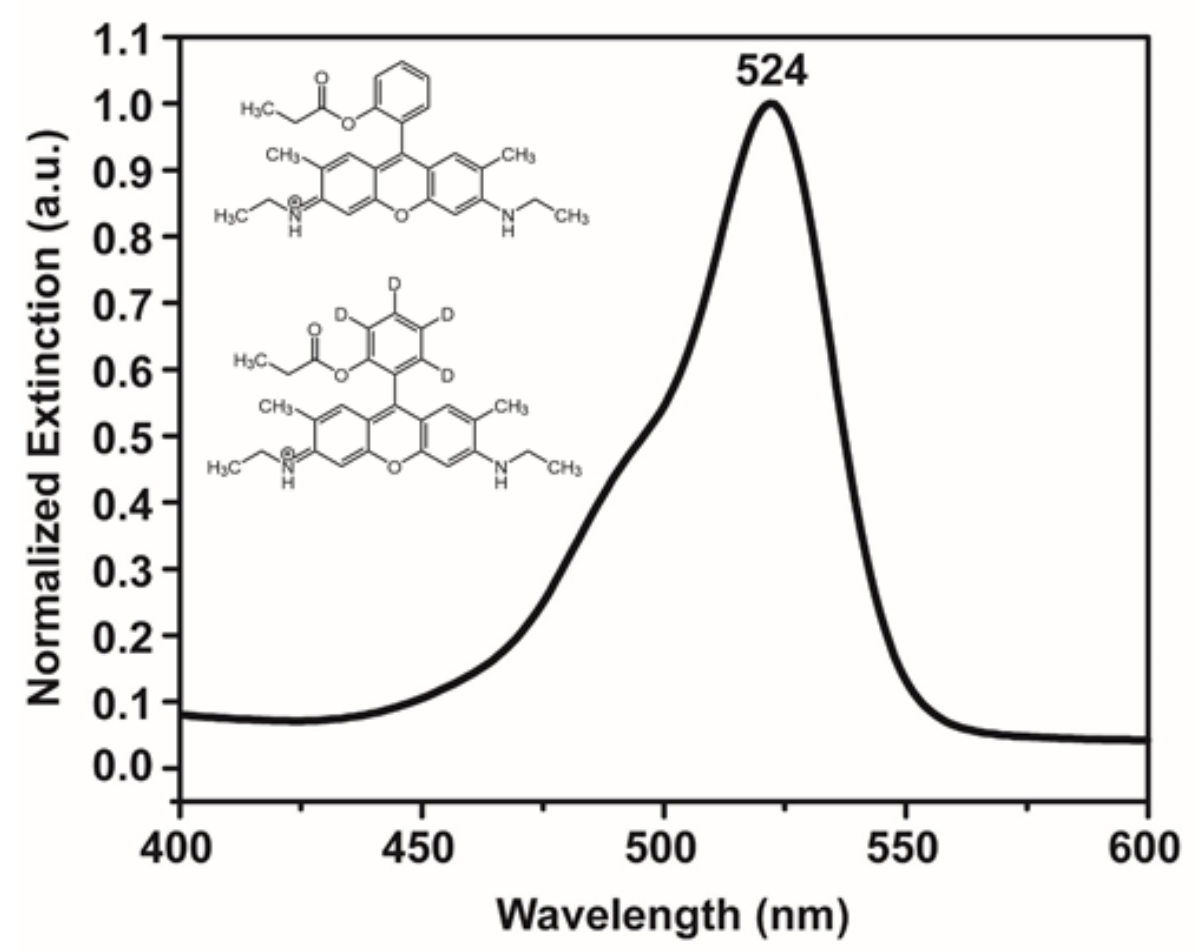

Figure S1. UV-Visible absorption spectra of $5.5 \times 10^{-5} \mathrm{M}$ R6G- $d_{0}$ and $5.5 \times 10^{-5} \mathrm{M}$ R6G- $d_{4}$ mixture ( $1.1 \times 10^{-4} \mathrm{M}$ total) in $\mathrm{MQ} \mathrm{H}_{2} \mathrm{O}$, demonstrating that there is no significant difference between the absorption spectra of R6G- $d_{0}$ and R6G- $d_{4}$. 

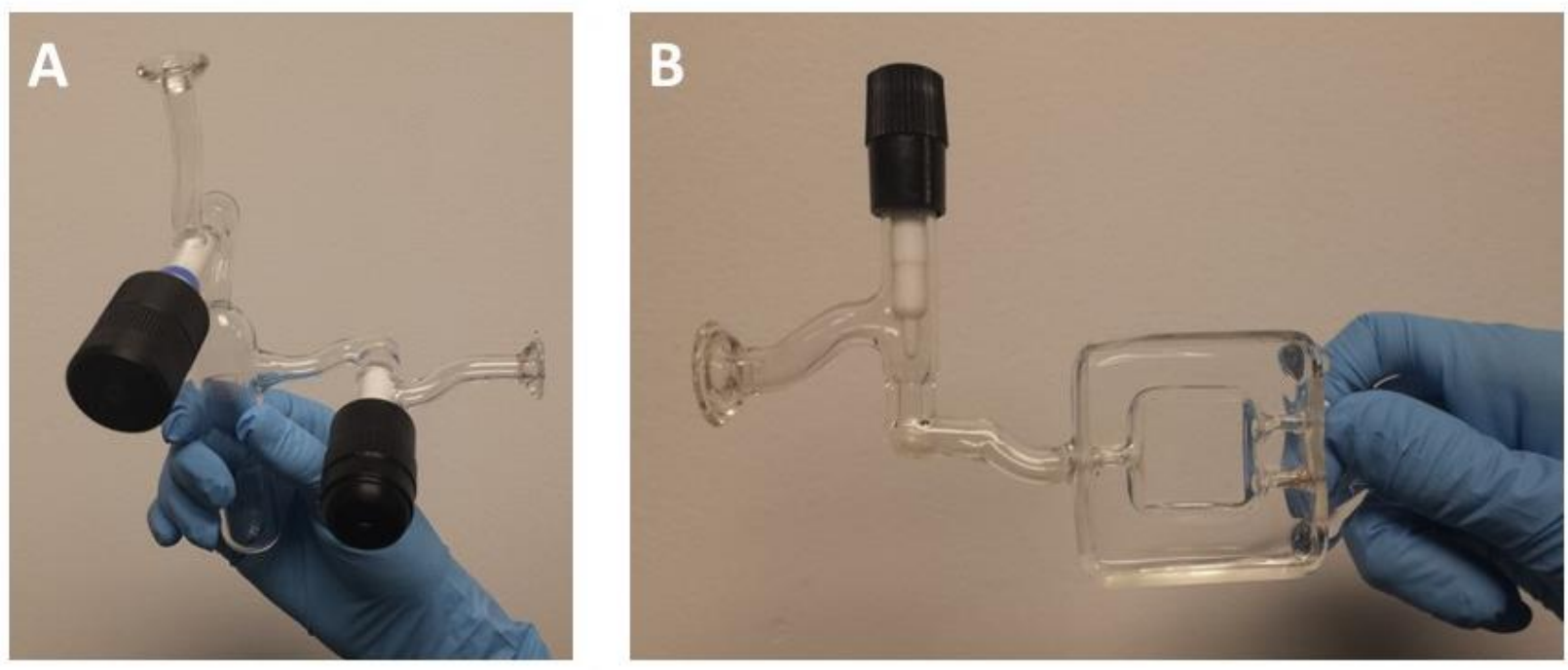

Figure S2. Photographs of A) custom-made glass freeze pump thaw cell and B) glass spectroscopic cell. 


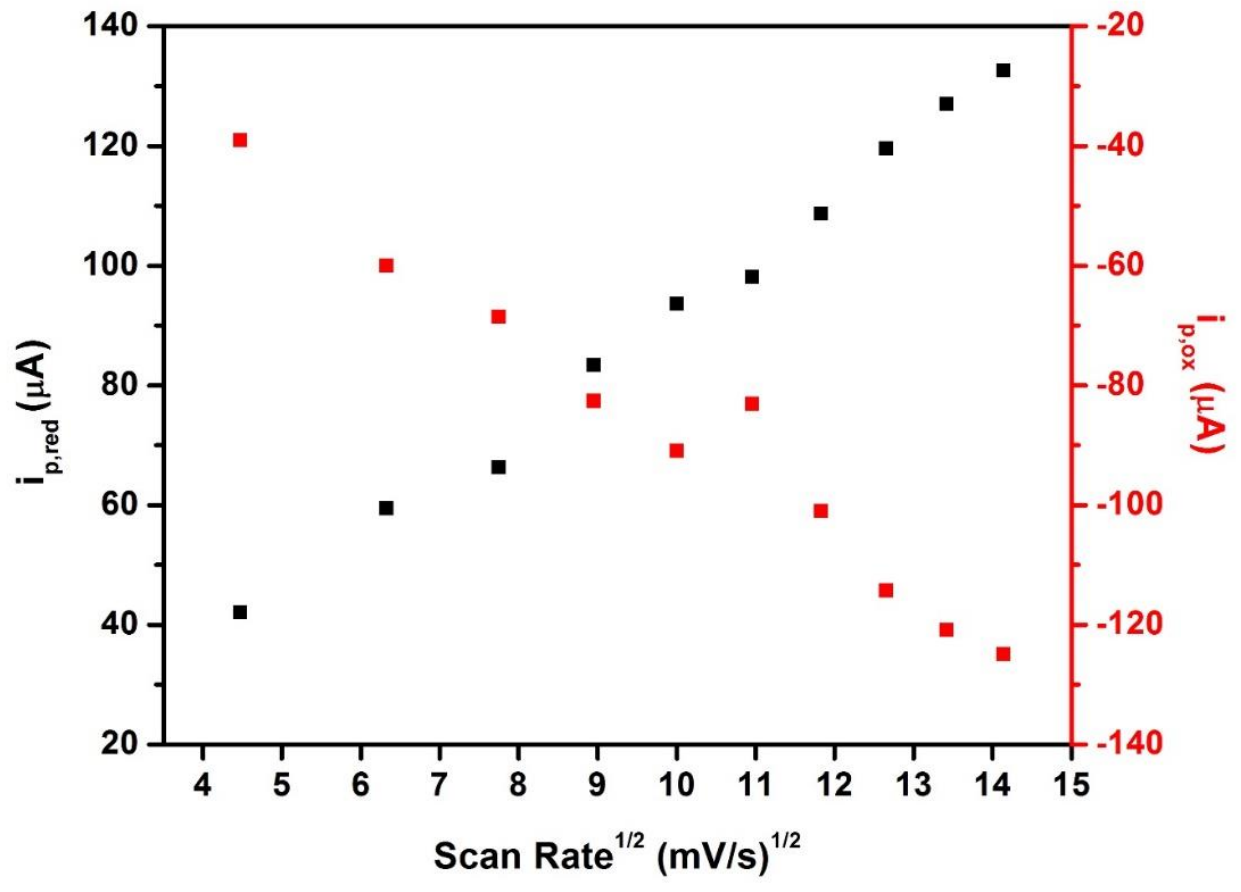

Figure S3. Square root of scan rate versus peak reduction (black) and oxidation (red) current for $1 \mathrm{mM}$ R6G in $100 \mathrm{mM}$ TBAP in acetonitrile which demonstrates well-behaved, reversible electrochemistry for R6G. (Ag wire working electrode, Pt wire counter electrode, Ag wire QRE) 


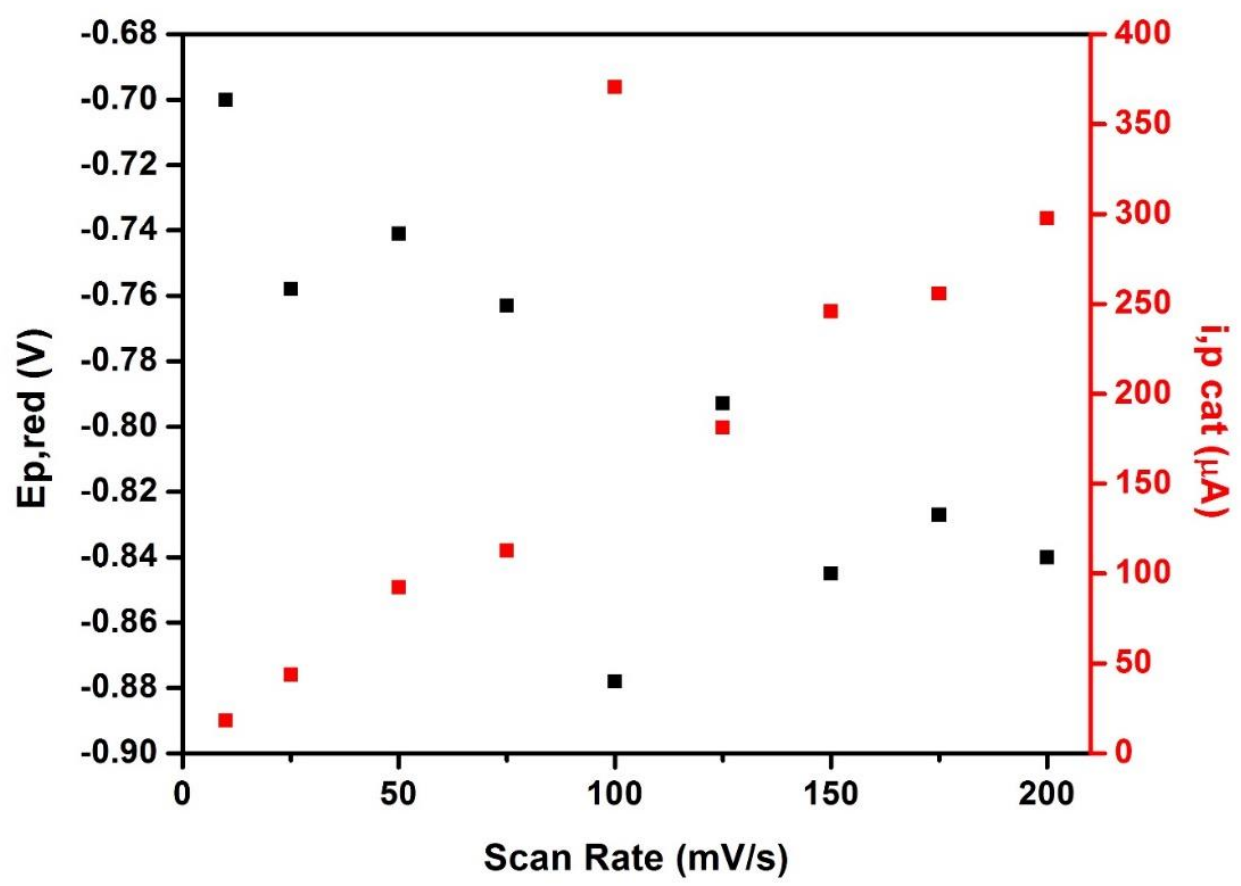

Figure S4. Scan rate versus peak reduction potential (black) and peak reduction current (red) for high coverage R6G adsorbed on AgNPs in 100 mM TBAP in acetonitrile which demonstrates uncompensated solution resistance and the presence of a surface-bound electroactive species, respectively. (Pt wire counter electrode, $\mathrm{Ag}$ wire $\mathrm{QRE}$ ) 


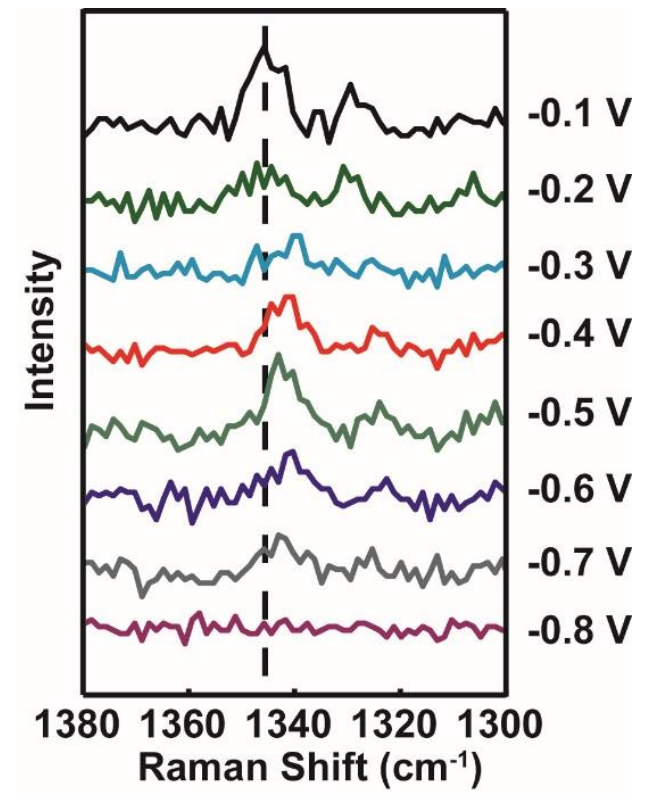

Figure S5. Representative SMSERS spectra displaying a blue shift in the $1350 \mathrm{~cm}^{-1}$ mode as a function of increasing negative potential. 

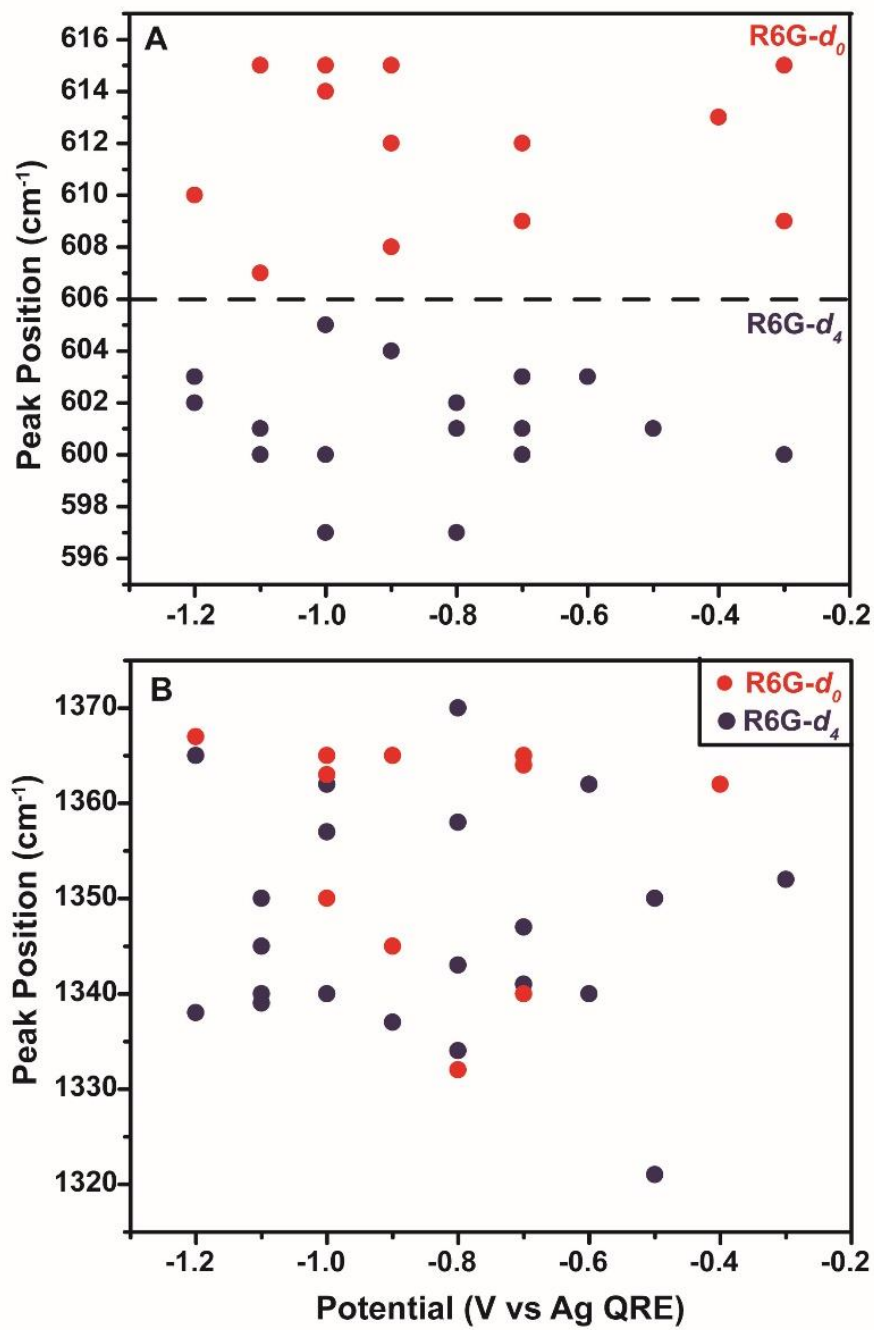

Figure S6. Plot of the (a) $600 \mathrm{~cm}^{-1}$ mode position and (b) $1350 \mathrm{~cm}^{-1}$ region mode versus SMSERS signal loss potential from R6G- $d_{0}$ (red) and R6G- $d_{4}$ (blue). 